\title{
DEVELOPMENT OF A 3D CADASTRE AUGMENTED REALITY AND VISUALIZATION IN MALAYSIA
}

\author{
Farah Ilyana Hairuddin ${ }^{1}$, Abdul Rauf Abdul Rasam ${ }^{1 *}$, Mohamad Hezri Razali ${ }^{1}$ \\ ${ }^{1}$ Centre of Studies for Surveying Science and Geomatics, Faculty of Architecture, Planning and Surveying, \\ Universiti Teknologi MARA, Shah Alam, Selangor Malaysia \\ Emails: farahilyanawork@gmail.com,rauf@uitm.edu.my*, hezrirazali@uitm.edu.my
}

\author{
Commission 4, WG 7
}

KEY WORDS: Augmented Reality (AR), 3D Cadastre ,Visualization, Strata Management.

\begin{abstract}
This paper discusses the capabilities of cadastre augmented reality (AR) and three-dimensional (3D) visualization in enhancing the stratified property visibility and information of the current strata plan in Malaysia. Currently, 2D information representation from the $2 \mathrm{D}+1 \mathrm{D}$ cadastre system is seen to be insufficient in serving real land management of the $3 \mathrm{D}$ aspect and property. Hence, toward a better digital 3D strata/property registration and land administration system in Malaysia, this study has explored the process in utilizing AR and 3D model to the current strata plan to enhance digital strata information contents and enabling the virtual strata plan presentation. The software used to develop the AR application smartphone was Unity3D software while Autodesk Revit applied to develop the 3D model and preparation of strata information. The interesting findings has been shown in this study. First result showed 3D models and strata parcel's attribute that has been developed for AR digital content preparation. Secondly, this 3D-AR processes can continuously gather of user's ambient information, conduct real-world recognition, and obtain real-world perception through smartphone device. Lastly, with utilization of AR technology in strata, it provides a more information to the strata plan without needing to change the current format of strata plan as the information are being displayed virtually onto the reality. With the integration of augmented reality and 3D visualization, the documentation of stratified properties in strata plan is potential to be enhanced from 2D planimetric to 3D representation. overlaid 3D model of the stratified property and standard strata information virtually on the present strata plan which has created an enhanced reality. This can allow the information to be viewed by more stakeholders with less restriction by using smartphone device.
\end{abstract}

\section{INTRODUCTION}

Augmented Reality (AR) is a technology that overlays virtual object onto the real world with the conceptual basis of requiring using computer graphic technique on an object which contains necessary information and present it virtually into the real environment, making it an enhanced reality. Application of AR is seen to be a potential problem solver in tackling limited space of a paper to show more information with its capability in retrieving more information virtually together with the implementation of smart phone application (Yuchen, 2017). Besides that, application of 3D visualization technique such as AR was suggested by Barzegar et al. (2021) in a study to develop spatial analysis framework in Australia 3D urban land administration as it is seen capable to represent results in a more tangible and understandable way.

The aim of the research is to make an enhancement on strata plan visualization for effective information deliverance holds on the surface of the land by exploring the capabilities of Augmented Reality (AR) integrated with 3D model to enable conveying the information of stratified properties on the land with partially immersive experience of AR technology. For this study, vision based was used where it works by aligning the virtual content with real world object based on the information from the pose estimation of the feature correspond. The digital strata plan acted as the object recognition, detection and tracking for the virtual content being augmented on it. Hence, the type of vision-based method used for this study was markerbased.
The inspiration on conducting this research was also based on the nation's project of implementing 3D Cadastre in Malaysia where due to the fasten development and urbanization, there are many infrastructures above and below the land surfaces which can involve different ownership even it is on the same column of land surfaces and these situations are no longer able to be portrayed on the 2D flat surface (Chong, 2006; Hassan and Nasruddin, 2008). Since 2006, the community are aware of the advantage of 3D representation in cadastral system. This is because, it has been discussed in previous researches that good and efficient land management in Malaysia can be obtained by opting 3D database in cadastral system and 3D cadastral can be made realizable with the development in 3D GIS (Hashim et al., 2018). Since the 3D geo-information sciences have been actively developed during the past two decades, 3D cadastre need to be evaluated from wider perspective in the future and advanced visualization such as augmented reality and virtual reality are included as the topic need to be address in the future (Döner, 2021).

There are many involvements in managing a strata scheme such as developers, joint management body and management corporation. Throughout the process of handing over the management between these three bodies, strata plan that is a legal document is also one of the documentation that is being handed over to the next management as it is a prove of ownership for each of the strata parcels. Besides that, certified strata plan also supplemented by management corporation to the 
rating authority to impose local government tax to the parcel owner.

Utilizing 3D model into 3D GIS and application of web-based system will bring benefit to the land administration system as it enables managing the strata rights in $3 \mathrm{D}$ and enhanced the information to be visualized in 3D. However, with application of $\mathrm{AR}$, the 3D visualization enhancement can be extended into legal documentation such as strata plan by utilizing 3D model into AR environment which enables producing 3D legal documentation due to the integration of augmented reality and $3 \mathrm{D}$ visualization. The integration enables viewing the stratified property in $3 \mathrm{D}$ on the $2 \mathrm{D}$ plan surface of the current format of strata plan. This could bring beneficial to many stakeholders of the legal documentation as more information can be retrieve in digital and virtually augmented on the physical documentation.

\section{RESEARCH FRAMEWORK}

Five (5) stages were involved in integrating augmented reality and 3D visualization as shown in Figure 1.

\begin{tabular}{|l|l|c|}
\hline $\begin{array}{c}\text { Preliminary Studies \& } \\
\text { Data Collection Stage }\end{array}$ & $\begin{array}{c}\text { Data Stage for AR Digital } \\
\text { Content }\end{array}$ & $\begin{array}{c}\text { Conversion Stage } \\
\text { for AR Preparation }\end{array}$ \\
$\begin{array}{l}\text { 3D Modelling \& AR } \\
\text { software selection and } \\
\text { Strata Plan as reference }\end{array}$ & $\begin{array}{l}\text { 3D model development and } \\
\text { strata information preparation } \\
\text { in Autodesk Revit }\end{array}$ & $\begin{array}{c}\text { 3D model material } \\
\text { conversion in } \\
\text { Autodesk 3Ds Max }\end{array}$ \\
\hline $\begin{array}{c}\text { AR and 3D Presentation Stage } \\
\text { for Strata Management Scheme }\end{array}$ & $\begin{array}{c}\text { Tangible Stage for AR } \\
\text { Development }\end{array}$ \\
\hline $\begin{array}{c}\text { 3D model and strata information } \\
\text { augmented on strata plan via } \\
\text { smartphone device }\end{array}$ & $\begin{array}{l}\text { 3D model and strata information } \\
\text { activation of Vuforia in Unity }\end{array}$ \\
\hline
\end{tabular}

Figure 1. Framework of Integrating AR with 3D model

The designation on the flow chart was inspired by the four phases required in order to develop complete AR application by Chi et al., (2013) and has also been applied by Williams et al., (2014).

\section{METHODOLOGY}

\subsection{Preliminary Studies \& Data Collection Stage}

During this stage, the tasks conducted consist of acquiring data to develop the 3D model of the stratified property and selecting compatible 3D model development and augmented reality software as shown in Figure 2.

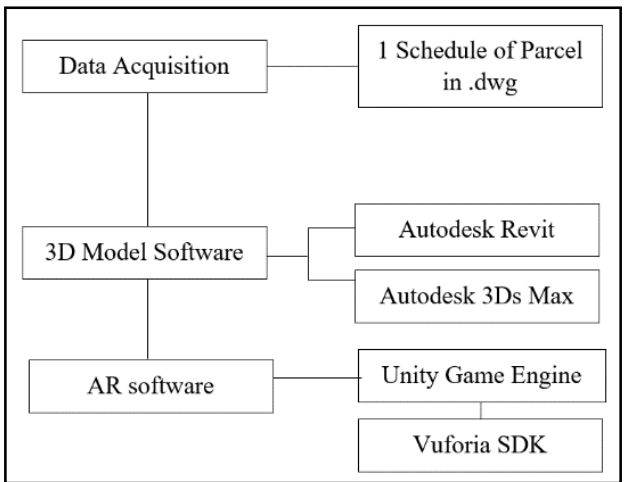

Figure 2. Framework of preliminary studies \& data collection stage
To generate 3D model of the building, the building's schedule of parcels (JP) was acquired as secondary data source. The horizontal dimension value in the JP acted as the building footprint while the vertical section value acted to extrude the building by inserting the value in elevation section in Autodesk Revit to enable the stratified property able to be visualized in $3 \mathrm{D}$ as in Figure 3. Due to unable to obtain the vector format of CPS, JP was used as reference to generate the 3D model. Besides, no significant impact due to using different type of plan as long as it provide sufficient information to develop 3D model to fulfill the scope of the work which is to generate 3D model for it to be used as AR digital content.

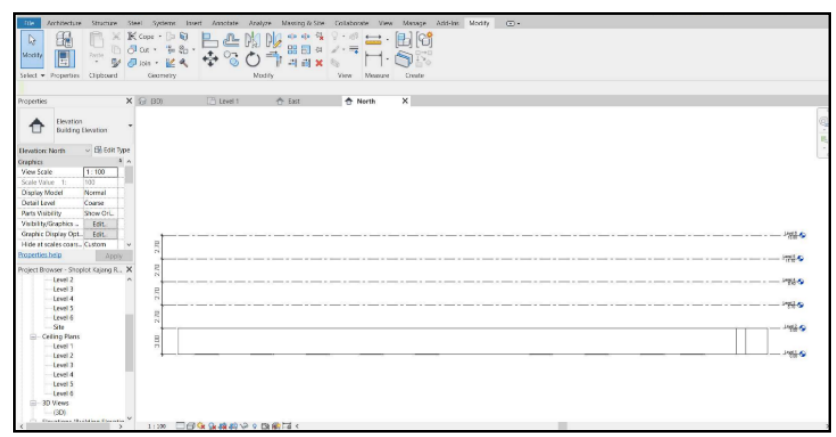

Figure 3. Inserting elevation value to extrude the building

As for 3D Model development, the software used was Autodesk Revit. Next, Autodesk 3Ds Max was used for the purpose of converting the material format of the $3 \mathrm{D}$ model to allow compatibility to be used in the game engine.

For AR development process, the game engine software used was Unity software. The AR environment activation in Unity was conducted with installation of Vuforia software development kit (SDK) into Unity. Besides that, to allow building the AR application into an Android smartphone device, Android Build Support was installed in Unity.

\subsection{Tangible Stage for AR Development}

Tangible stage started with selecting software and application that support AR environment. Besides that, it also involved selecting and preparing portable device to display the output. For this study, Unity has been chosen as the game engine software for AR development process and smartphone device was selected as the tangible tool to display the output.

Three 3D model were imported into Unity and Vuforia SDK has been activated in Unity to activate the project into AR environment and digital JP was registered by Vuforia system as the marker for the $3 \mathrm{D}$ models to be augmented on top of the physical version of JP. Figure 4 shows the general framework of this stage.

The main task in tangible stage consists of preparing Unity for AR environment, developing AR project and build $A R$ application into Android device. Below is brief explanation for each of the task.

\section{Unity for AR environment preparation}

There were three initial settings conducted to make Unity able to support AR environment and build the application for Android device. The three initial 
settings consist of installation of modules in Unity, configuration of Android as platform for AR process and activation of Vuforia as AR SDK in Unity.

(b)

\section{Developing AR project}

With activation of Vuforia, AR features in Vuforia engine were used in unity for further AR development process. Two features in Vuforia engine has been used which is ARcamera and Image Target.

ARcamera is a special camera type used in Unity that supports AR application for handheld devices while Image Target is responsible in registering flat images database for the attachment of the digital contents. At this stage, preparation of Schedule of Parcel as the image target and 3D model of the stratified floor together with parcels' attribute as the digital contents was conducted.

Three C\# language scripting was developed and attached to the 3D models in Unity to allow strata information retrieval from each parcel of Floor 1 and Floor 2 3D model during running the AR application in smartphone device. The three scripting consists of Strata Schedule Parser, Parcel's Metadata and Parcel's Information Retrieval. Brief explanation on the scripts are as below.

\section{Strata Schedule Parser Script}

Responsible in reading the .txt file of Room Schedule and add the parcel information onto the 3D model by identifying the ElementID in the txt file and match it with ElementID of the 3D model.

\section{Parcel's Metadata Script}

Responsible in attaching parcel information to its 3D model.

\section{Parcel's Information Retrieval Script}

Display information of the parcel when the 3D model is being touched on smartphone device's screen.

\section{AR application built into Android device}

The Augmented Reality application was prepared and built in the format of Android Package Kit (.APK). The Build and Run options in Unity has built the APK AR application file to the smartphone device through USB debugging by enabling developer mode in the smartphone device.

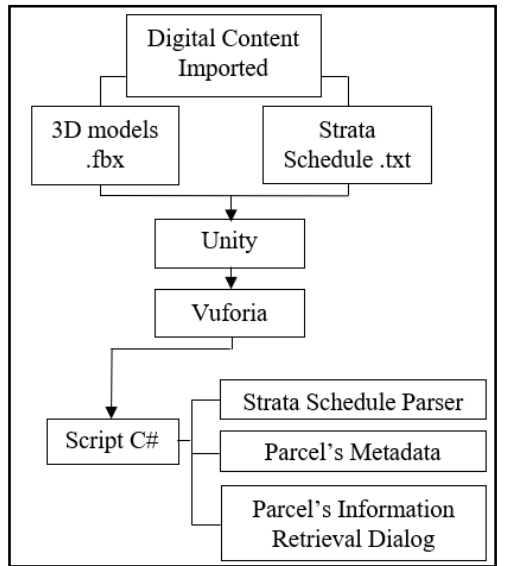

Figure 4. General framework of tangible stage for AR development

\subsection{AR and 3D Presentation Stage for Strata Management Scheme}

The presentation stage involved visualization of Floor 1, Floor 2 and Block A of LCA Mawar's 3D model and each parcel's strata information as the digital content of the JP through the AR application built into the smartphone device. The presentation stage involved using smartphone device as the tangible tool and the sensor built in the smartphone device has allowed visualizing the digital content in reality.

The augmentation onto the physical JP occurred due to the four basic operation conducted by the smartphone device camera upon tracking JP as the marker. The basic operation is as shown in Figure 5.

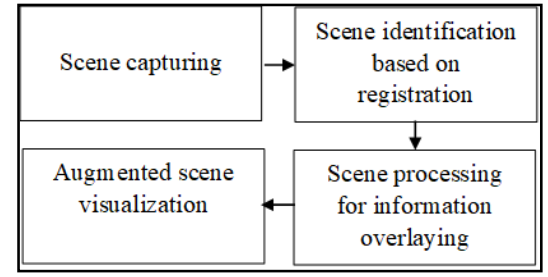

Figure 5. 4 basic operation occurred in presentation stage (Khan et al., 2015)

\section{RESULT AND ANALYSIS}

\subsection{D Strata information for AR digital content}

The digital content that has been developed for preparation of AR digital content consists of 3D model of Floor 1, Floor 2 and the whole building of low-cost apartment Mawar Block A and attribute of parcels' strata information. The 3D strata information was prepared in Autodesk Revit 2019. The decision in choosing Revit as medium to develop 3D Model was due to its usage in previous research during data preparation stage before integrating the data with AR technology. Examples of studies can be seen conducted by Carrión-Ruiz et al. (2019) for cultural heritage, Mirshokraei et al. (2019) and Williams et al. (2014) for structural elements' quality management. The 3D modelling technique has been generated using conventional technique where the Strata Plan was used as the reference to generate the 3D model. The 3D Model format has been 
prepared according to the 2D documentation format as shown in Figure 6 as specified in Strata Title Act and survey circular.

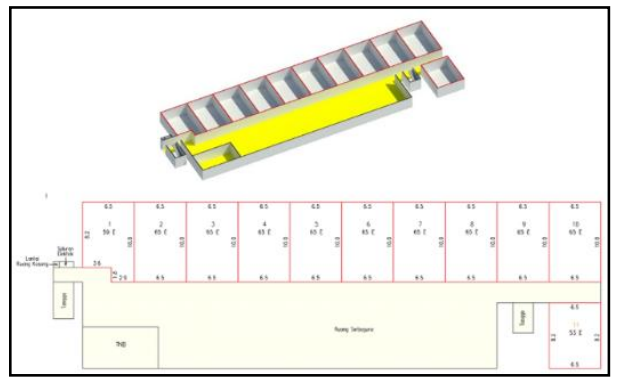

Figure 6. 3D Model and 2D drawing of Floor 1

\subsubsection{Horizontal Dimension of the Parcel}

In Autodesk Revit 2019, the process of defining the parcel's dimension involved defining the wall properties such as type of wall and location line of the wall. Since the dimensions were defined through walls instead of 2D line, Measure Tool using Aligned Dimension option and on-screen flip controls was frequently used to ensure the parcel's dimension correctly defined from centre of the wall.

\subsubsection{Strata Parcel Boundary}

In Autodesk Revit 2019, by default, the area was computed from the interior face of the wall as in Figure 7 due to the 'Room Bounding' attributes in the wall properties. To delineate the Parcel Boundary from centre of the wall, it is crucial to untick the 'Room Bounding' and requires usage of 'Space Separator' tool in 'Analyse' tab where the result is shown in in Figure 8.

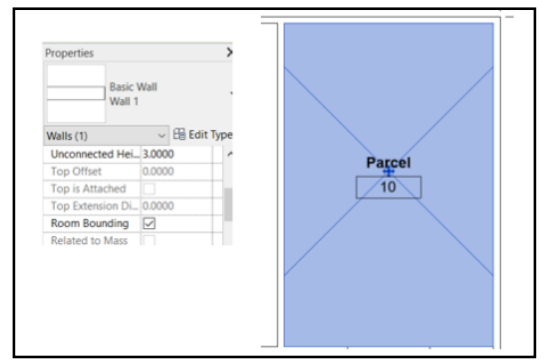

Figure 7. Room Bounding causing delineating the area from interior face.

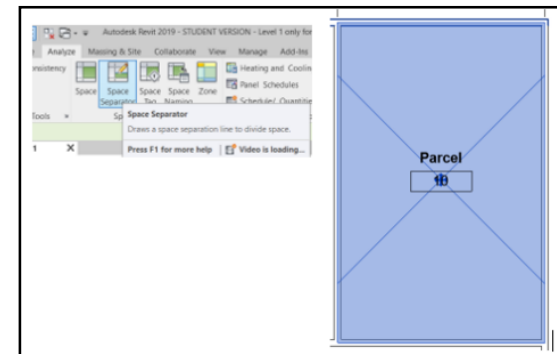

Figure 8. Delineating the Parcel Boundary from the wall centerline using Space Separator tool.

\subsubsection{Documenting Strata Information}

The parcels' strata information was stored in Space Properties in Autodesk Revit 2019 as the parcel boundary was delineated using Space tool after using Space Separator tool onto the parcels' wall. Figure 9 shows the strata information for parcel 10 appeared in Space Properties upon clicking the parcel.

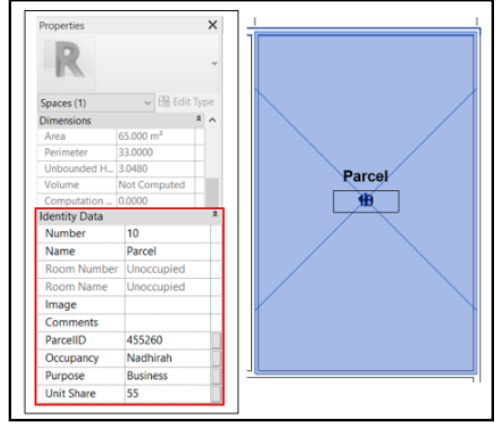

Figure 9. Parcel's Strata Information stored in Space properties

To be used as AR digital content, the strata information was prepared as a schedule and exported in .txt file to be used in Unity software as shown in Figure 10.

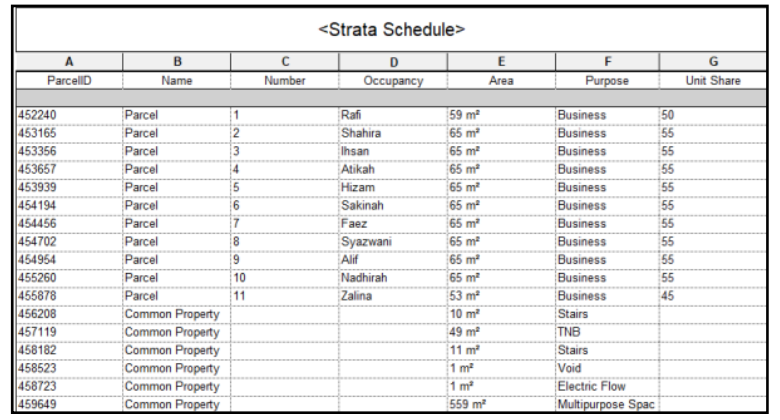

Figure 10. Strata Schedule of Floor 1 in Autodesk Revit

\subsection{Utilization of Digital Contents into AR Environment}

The two digital content that has been prepared in Autodesk Revit 2019 was utilized into Unity for AR development. The digital content consists of 3D model of Floor 1, Floor $2 \&$ the whole building in the format of Filmbox (.fbx) and attribute of parcels' strata information in text-formatted data (.txt) format. Figure 11 shows the result of utilizing the 3D models as digital content into AR environment in Unity software while Figure 11 (i) and (ii) shows how strata information was managed in Unity software.

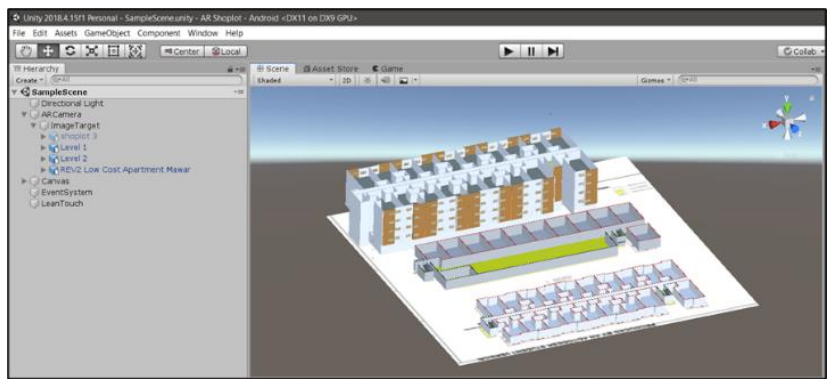

Figure 11. 3D models utilized into AR environment in Unity software

During system testing in Unity software, upon clicking the parcel's ID under the Hierarchy as shown in Figure 12(i), its strata information for the parcel appeared in the Metadata (script) as shown in Figure 12 (ii). 


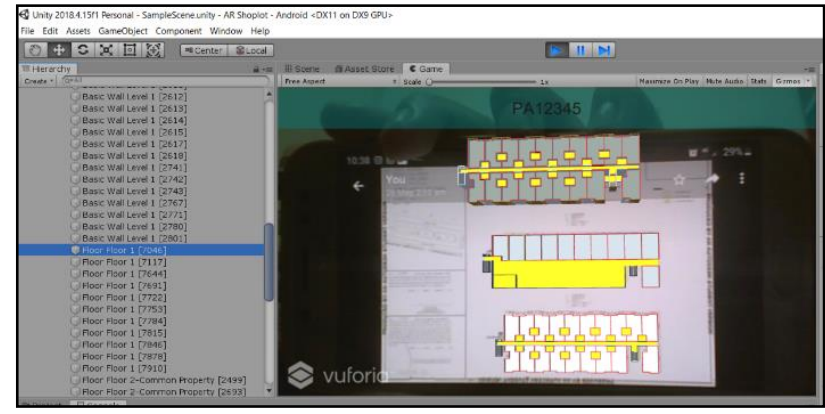

Figure 12 (i). Strata information managed in Unity software

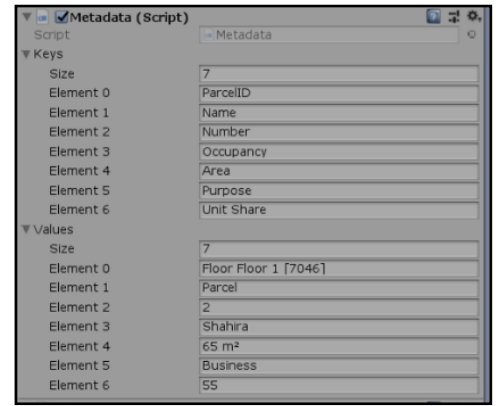

Figure 12 (ii). Strata information for Parcel ID "Floor Floor 1

[7046]"

Format and conversion of material format played a huge role in enabling the digital content able to be used in AR environment while ID assigned on each building component of the 3D models played an important role in enabling each of the parcel's strata information registered to the parcel in the 3D model.

\subsubsection{D Model Format Compatibility and Retention of its Material into Unity}

Unity software supported .fbx format as it keep sufficient data for visualization while the usage of Autodesk 3Ds Max served the purpose in making the material format compatible with Unity. In Autodesk 3Ds Max, the 3D models was converted its material into standard material to enable the colored material retain in Unity. Rohde (2014) stated that Standard Materials is a common practice to be used to ensure the materials able to be exported into Unity or any game engine. Unity also supported 3D model in .fbx format by Autodesk Revit but it does not support the material assigned by Autodesk Revit which led to the 3D model to be in generic grey as shown in Figure 13 . Hence, it is crucial to convert the material format in 3Ds Max.

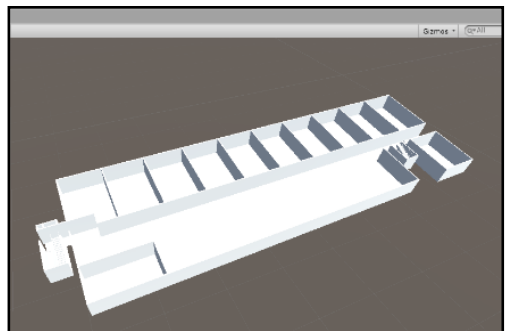

Figure 13. 3D model in the format of .fbx imported from Autodesk Revit 2019 into Unity

\subsubsection{Condition of the 3D Model in Unity Game Engine}

Upon exporting the 3D models in .fbx format into Unity Game Engine after 3D models material converted into standard material, the 3D models were able to be visualized with its material retained in Unity and the IDs of the building component was able to be read by Unity as shown in Figure 14.

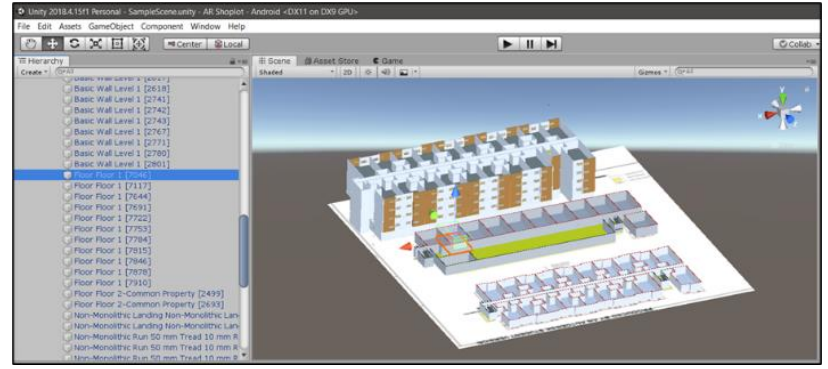

Figure 14. ID for each of the building component

The study has linked the parcels' strata information to the 3D model's building component by matching the ID of the parcel's wall with the ID of the parcel's strata information through developing C\# language scripting in Unity.

\subsubsection{Evaluation on Image of Schedule of Parcel's Trackability as the Marker.}

The capability of the 3D models able to virtually overlaid on the physical Schedule of Parcel (JP) was due to constant calculation conducted in AR system to calculate distance and orientation from the device's observation to the predefined pattern in reality (Hwang \& Chu, 2016) which upon detecting the predefined pattern, the setup virtual 3D models were projected on the predefined pattern that acted as the marker. Figure 15 shows the result of JP's trability rating evaluated by Vuforia which the rating obtained was 2 out of 5 despite having many trackable features generated by Vuforia as shown in Figure 16. Though the rating was very poor, during the running of AR application, the marker can still be tracked, and the 3D models were able to overlaid on the physical plan of JP.

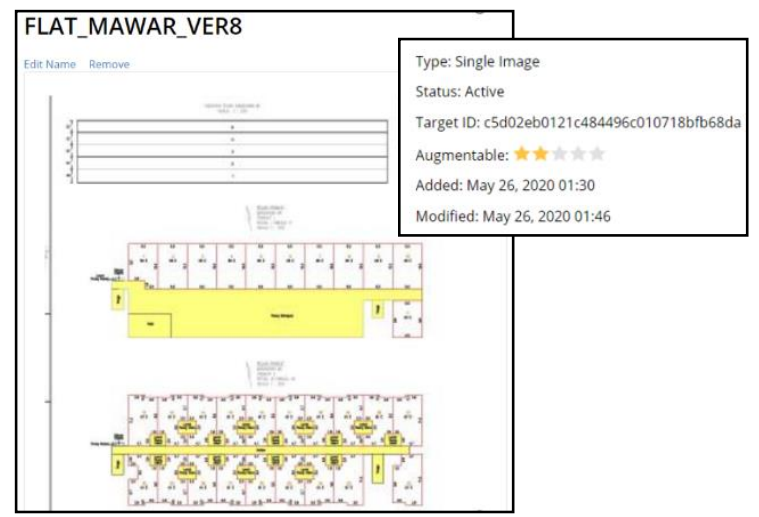

Figure15. Schedule of Parcel's trackability rating 


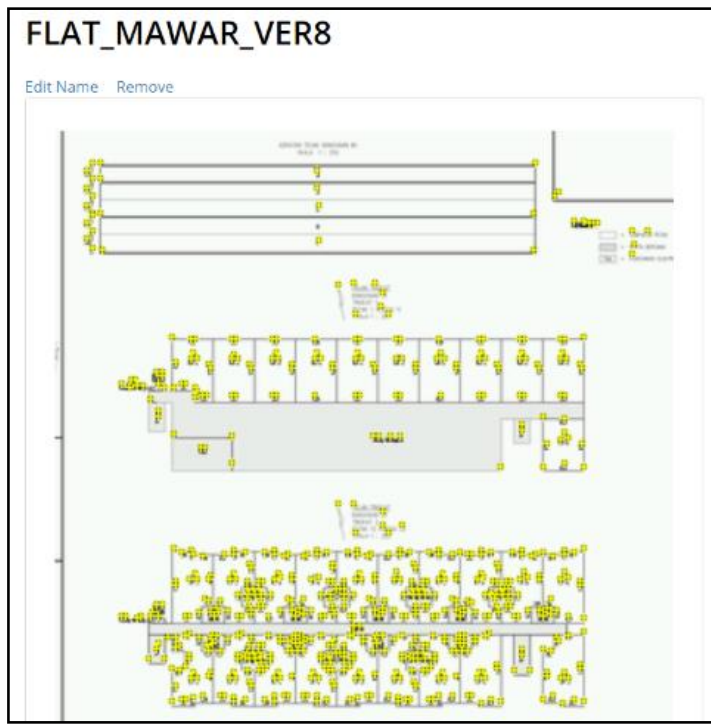

Figure 16. Trackable features generated by vuforia

the image of JP was difficult to obtained higher trackable rating due to repetitive pattern, features and lack of contrast. Attributes of an ideal image target stated in Vuforia Developer Library consists of rich in detail, good contrast, no repetitive patterns and format of .PNG and JPG. Through these attribute, trackable features were generated by Vuforia as shown in crossed shape yellow color in Figure 16. The higher the trackable features able to be generated, the higher the trackable rating will be assigned.

\subsubsection{Managing Strata Information in AR environment}

The scope of this research does not focus on strata registration. Rather, it was an exploration on how retrieving an attribute of information from 3D model works in AR environment. Since exploration on how data in .xml format lead to time consumption, the strata information has been compiled and exported into .txt format in Autodesk Revit. To link the building parcels to its data in Unity software, three components for data management have been developed by using C\# language scripting. The three component consists of Strata Schedule Parser, Parcel's Metadata, and Parcel's Information Retrieval. Figure 17 shows the architecture of the data management and the result is as shown in Figure 12 (ii).

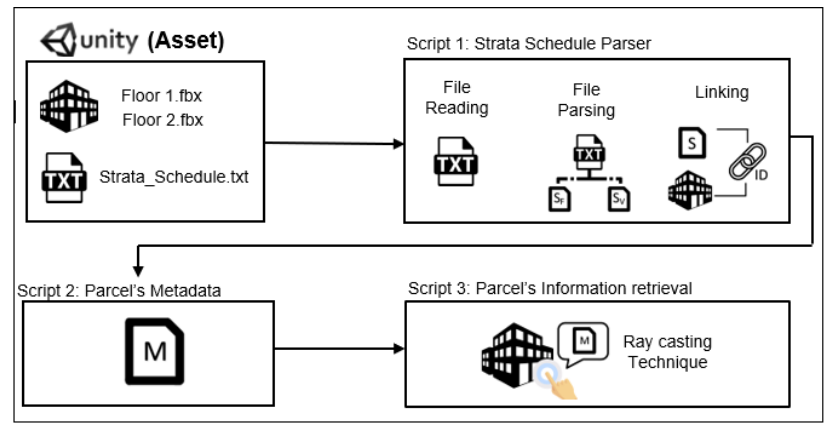

Figure 17. Architecture of strata data management in Unity

Strata parcel's information was able to retrieved by touching the parcel in its 3D model using finger due to ray casting technique applied in the scripting. The insertion of box collider as shown in Figure 18 onto each of the parcel has triggered the ray casting technique to response the action of touching the parcel in $3 \mathrm{D}$ model by using finger or mouse. Hence allowing strata parcel's information able to be retrieved in AR environment.

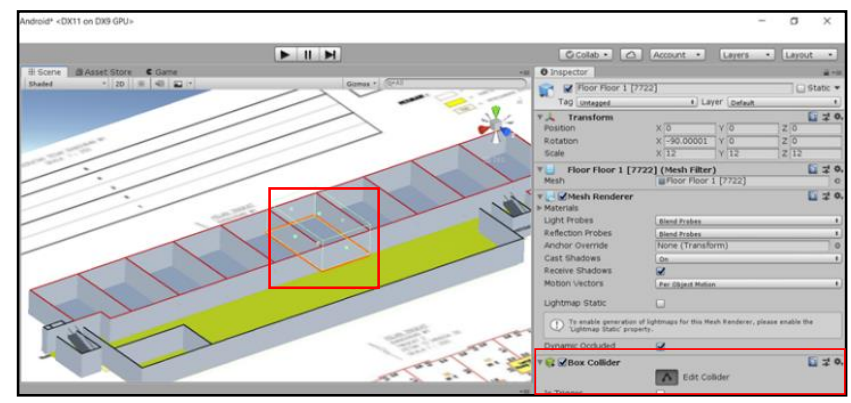

Figure 18. Box collider to trigger ray casting function

\subsection{Integration of Augmented Reality and 3D Visualization for Strata Management Scheme}

At the end of the process, Unity software successfully packaged the project into an AR application in the format of Android Package Kit (.apk) and built into an android device to enable the realization of integrating $\mathrm{AR}$ and $3 \mathrm{D}$ visualization for strata management scheme.

Figure 19 (i) shows the physical strata plan where Hashim et al., (2018) describe that the current strata plan comprises of parcel dimension horizontally and vertically represented in $2 \mathrm{D}$, location plan and certificate of respective figure while Figure 19 (ii) displays the same strata physical plan with element described by Hashim et al;., (2018) retained with appearance of $3 \mathrm{D}$ visualization of the strata floor and building acted as the additional information to the plan. Besides that Figure 19 (ii) also shows the strata parcel's information retrieved when the finger touches the parcel in the 3D model. The augmentation of these digital contents onto the physical strata plan was conducted using Android smartphone device that acted as the platform of AR technology deployment.
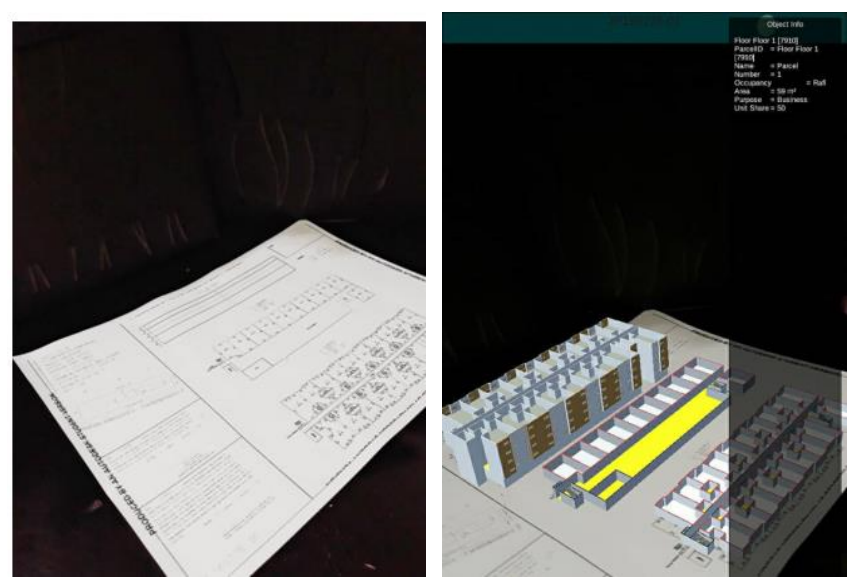

Figure 19 (i). physical version of JP (ii) physical version of JP with augmented digital contents.

From the result obtained it can be seen that the physical plan of JP appears to be more comprehensive in aspect of visualization and information retrieval where the additional content appears digitally while the format of current strata plan remains the same. Werner (2018) stated that integration of AR technology with paper maps enable paper maps potential to be included into 
chain of digital devices as it involve coding some data and metadata onto the map that can lead to intensive exploration on geospatial data from the real world. With AR technology, the value of paper map in the era of digital can be upgraded.

There are four phases required in building a full AR system Chi et al., (2013) which is data phase, computing phase, tangible phase and presentation phase as shown in Figure 20 which the study has fulfilled.

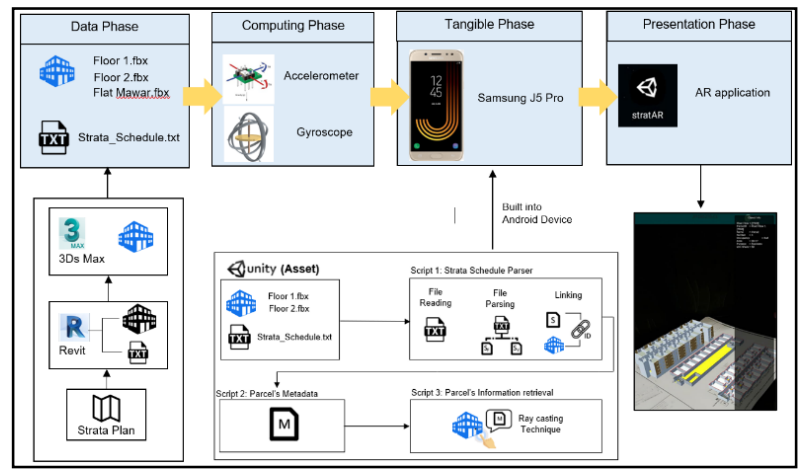

Figure 20. Architecture of AR application

\section{CONCLUSION}

Augmented reality as one of the emerging trends in 3D visualization in aspect of visualization platforms. With the AR application successfully built into the Android device, the integration of $\mathrm{AR}$ and $3 \mathrm{D}$ visualization has successfully realized. the visualization enhancement onto the strata plan without changing the format of the current strata plan. Instead, the image of the strata plan in the format of .PNG was registered as the marker in the Unity software to enable the digital content able to be augmented on top of the physical strata plan when the smartphone's camera tracked the marker which created an augmented map.

With current progress in improving the management of strata objects information in $3 \mathrm{D}$, preparation on producing legal documentation that support 3D visualization have the potential to be conducted through augmented reality to enable the stakeholders to receive the similar information as registered which is in $3 \mathrm{D}$.

There are several recommendations in the research of $\mathrm{AR}$ application for future works. In aspect of preparing AR digital content:

a) Developing 3D model from data obtained acquired using Geo-technologies equipment such as Terrestrial Laser Scanner and Unmanned Aerial Vehicle.

b) Explore topology function for $3 \mathrm{D}$ model development.

c) Prepare AR digital content in other format such as Industry Foundation Classes (IFC) and Extensible Markup Language (XML).

In aspect of managing strata information in AR environment:

(a) Improvise the current scripting that can support more strata file and other data format.

(b) Utilize the scripting of the 3D strata registration into AR environment.
Lastly in aspect of AR application:

(a) Insert function that allows highlighting the parcel being selected at that time.

(b) Provide more user interaction function (c) Provide navigation to the strata parcel by AR.

\section{ACKNOWLEDGEMENT}

The authors would like to express appreciation to the Department of Survey and Mapping Malaysia (JUPEM) for providing cadastral inputs in this research paper. The authors would also like to sincerely thank Universiti Teknologi MARA Selangor for providing LESTARI Research Fund (600IRMI5/3/LESTARI (005/2018)

\section{REFERENCES}

Barzegar, M., Rajabifard, A., Kalantari, M., \& Atazadeh, B., 2021: A framework for spatial analysis in 3D urban land administration - A case study for Victoria, Australia. Land Use Policy, 105766. https://doi.org/10.1016/J.LANDUSEPOL.2021.105766

Carrión-Ruiz, B., Blanco-Pons, S., Duong, M., Chartrand, J., Li, M., Prochnau, K., ... Lerma, J. L., 2019: Augmented Experience to Disseminate Cultural Heritage: House of Commons Windows, Parliament Hill National Historic Site (Canada). ISPRS Annals of the Photogrammetry, Remote Sensing and Spatial Information Sciences, 42(2/W9), 243-247.

Chi, H. L., Kang, S. C., \& Wang, X., 2013: Research trends and opportunities of augmented reality applications in architecture, engineering, and construction. Automation in Construction, 33, 116-122.

Choon, T. A. N. L., \& Hussin, K. B., 2011: Property formationChange in land related legal document.

Chong, S. C., 2006: Towards a 3D Cadastre in Malaysia - An Implementation Evaluation (Issue September).

Doner, Fatih, 2021: Analysis of literature in 3D Cadastre. International Journal of Engineering and Geosciences2021;6(2);90-97.

Erba, D. A., Aien, A., Grant, D., Kalantari, M., Karki, S., Shojaei, D., Thompson, R., Muggenhuber, G., Navratil, G., Dixit, N., \& others., 2018: FIG publication Best Practices 3D Cadastres.

Fritsch, D., \& Klein, M., 2018: 3D and 4D modeling for AR and VR app developments. Proceedings of the 2017 23rd International Conference on Virtual Systems and Multimedia, VSMM 2017, 2018-Janua, 1-8.

Hashim, M. N., Hassan, M. I., \& Abdul Rahman, A., 2019: Mobile Indoor Laser Scanning For 3d Strata Registration Purposes Based On Indoorgml. International Archives of the Photogrammetry, Remote Sensing and Spatial Information Sciences - ISPRS Archives, 42(4/W16), 241-245. 
Hashim, M. N., Hassan, M. I., \& Rahman, A. A,. 2018: 3D modelling towards strata registration. International Archives of the Photogrammetry, Remote Sensing and Spatial Information Sciences - ISPRS Archives, 42(4/W9), 23-26.

Hwang, J.-T., \& Chu, T.-C., 2016: 3D Building Reconstruction By Multiview Images and the Integrated Application With Augmented Reality. ISPRS - International Archives of the Photogrammetry, Remote Sensing and Spatial Information Sciences, XLI-B1, 1235-1241.

Hassan, M. I., Ahmad-Nasruddin, M. H., Yaakop, I. A., \& Abdul-Rahman, A., 2008: An Integrated 3D Cadastre-Malaysia As an

Example.

Jamil, H., Noor ISA, M., Teng, C., CHAN, K. L., Abdul Rahman, A., Amri Musliman, I., Ujang, U., Hassan, I., Siew, B., Karim, H., Amalina Zulkifli, N., Azri, S., \& Van Oosterom, P., 2017: Converting The Strata Building to LADM Converting The Strata Building to LADM (8920)

Khan, A., Azhar, R., Kusro, S., \& Mahfooz, S., 2015: Rebirth of Augmented Reality - Enhancing Reality via Smartphones. Bahria University Journal of Information \& Communica Tion Technologies, Vol. 8, Issue 1.

Mirshokraei, M., De Gaetani, C. I., \& Migliaccio, F., 2019: A web-based BIM-AR quality management system for structural elements. Applied Sciences (Switzerland), 9(19).

Milgram, P., \& Kishino, F., 1994: Taxonomy of mixed reality visual displays. IEICE Transactions on Information and Systems.

https://www.researchgate.net/publication/231514051_A_Taxon omy_of_Mixed_Reality_Visual_Displays

Qiao, X., Ren, P., Dustdar, S., Liu, L., Ma, H., \& Chen, J., 2019: Web AR: A Promising Future for Mobile Augmented Reality-State of the Art, Challenges, and Insights. Proceedings of the IEEE, 107(4), 651-666

Rohde, P., 2014: Solved: Re: No fbx textures on export Autodesk Community - 3ds Max.

Werner, P. A., 2017: Augmented Reality and Perception of Analogue and Digital Images and Maps. Proceedings, 1(10), 56 .

Williams, G., Gheisari, M., Chen, P. J., \& Irizarry, J., 2014: BIM2MAR: An efficient BIM translation to mobile augmented reality applications. Journal of Management in Engineering, 31(1).

Yuchen, L., 2017: Augmented Reality Visualization of Building Information Model. 